$\mathrm{OR}=9.3$ for adults with DScores of 2-3 and 4-6 [compared with DS 0-1], respectively). Odds of CS (vs FS) were also higher with higher DScores $(\mathrm{OR}=6.9$ and $\mathrm{OR}=7.6$ for adults with a DS of 2-3 and 4-6 [compared with DS 0-1], respectively).

Conclusion Smoking is highly prevalent in patients with pCCLE. DScores were positively associated with CS and inversely associated with FS. Smoking cessation is particularly important for adults with pCCLE, and such efforts should target individuals from the most disadvantaged sociodemographic groups.

Acknowledgements The GOAL Cohort is supported by the Centers for Disease Control and Prevention (CDC) Grant 1U01DP005119. The content of this research is solely the responsibility of the authors and does not necessarily represent the official views of the CDC. The authors have no conflicts of interest to declare.

\section{P58 SYSTEMIC LUPUS ERYTHEMATOSUS IN NATIVE SUB- SAHARAN AFRICANS: A SYSTEMATIC REVIEW AND META-ANALYSIS}

\begin{abstract}
${ }^{1}$ Mickael Essouma, ${ }^{1} J a n$ René Nkeck, ${ }^{2}$ Francky Teddy A Endomba, ${ }^{3,4}$ Jean Joel Bigna, 1,5 Madeleine Singwe-Ngandeu, ${ }^{6}$ Eric Hachulla. ${ }^{1}$ Faculty of Medicine and Biomedical Sciences, University of Yaoundé I, Yaoundé, Cameroon; ${ }^{2}$ University of Bourgogne, Dijon, France; ${ }^{3}$ Centre Pasteur of Cameroon, Yaoundé, Cameroon; ${ }^{4}$ Faculty of Medicine, University of Paris Sud XI, Le Kremlin-Bicêtre, France; ${ }^{5}$ Yaoundé Central Hospital, Yaoundé, Cameroon;

${ }^{6}$ Claude Huriez Hospital, Lille University, Lille, France
\end{abstract}

\subsection{6/lupus-2020-eurolupus. 105}

Background This systematic review of literature and meta-analysis aimed to determine the prevalence, phenotype and treatment of systemic lupus erythematosus (SLE) in Native subSaharan Africans.

Methods PubMed, EMBASE, Web of Science, African Journals Online, and Global Index Medicus as well as references of retrieved papers were searched to select studies addressing SLE in Native sub-Saharan Africans and published during January 1, 2008- October 7, 2018. Results were pooled through narrative review and random-effects model. Heterogeneity $\left(\mathrm{I}^{2}\right)$ was assessed via the $\chi^{2}$ test. Pooled estimates are expressed with 95\% confidence intervals. This study is registered with PROSPERO: registration number CRD42019139226.

Results Fifteen hospital-based studies were included out of 1502 records. The pooled prevalence of SLE was $1.7 \%(0.8-$ 2.9). The mean age at diagnosis ranged from 28.8 to 39.2 years. The female proportion was $88 \%-100 \%$. Rheumatological (5.1\%-99.9\%), dermatological (4.3\%-100\%) and hematological (1.4-86.9\%) manifestations were the commonest. Patients had a high seroprevalence for anti-ribonucleoprotein 57.9\% (36.4-77.9), anti-Smith 53.5\% (40.4-66.2), anti-Sjogren syndrome antigen A $45.6 \%(19.2-73.4)$ and anti-Sjogren syndrome antigen B 33.7\% (13.6-57.6) autoantibodies. The most used treatments were corticosteroids 99\% (94.9-100) and antimalarials 62. 8\% (23.3-94.1). The pooled mortality rate was $10.3 \%$ (3.3-20.6); mainly due to infections, kidney and neurological involvement.

Conclusions Over the last 30 years, SLE was not rare among Native sub-Saharan Africans and its featured characteristics were earlier onset, female predominance, and high seropositivity for extractable nuclear antigen autoantibodies. The standard treatments were corticosteroids and antimalarials. The mortality rate was high. Population prevalence and incidence as well as full description of SLE characteristics in Native subSaharan Africans are needed.

\section{P59 PREDICTORS OF RENAL SURVIVAL IN A COHORT OF PATIENTS WITH LUPUS NEPHRITIS WITH MORE THAN 30 YEARS OF FOLLOW-UP}

${ }^{1}$ Filipa Farinha, ${ }^{2}$ Ruth J Pepper, ${ }^{3}$ Daniel G Oliveira, ${ }^{1}$ Thomas McDonnell, 'David A Isenberg, ${ }^{1}$ Anisur Rahman. ${ }^{1}$ Centre for Rheumatology, University College London, London; ${ }^{2}$ Centre for Nephrology, University College London-Royal Free Campus, London, UK; ${ }^{3}$ Internal Medicine Dept., Centro Hospitalar e Universitário do Porto, Porto, Portugal

\subsection{6/lupus-2020-eurolupus. 106}

Background Despite the improvement in survival of patients with lupus nephritis ( $\mathrm{LN}$ ) over the last decades, LN is associated with progression to end-stage renal disease (ESRD) in a significant proportion of patients. We aimed to investigate the factors influencing renal survival in patients with LN.
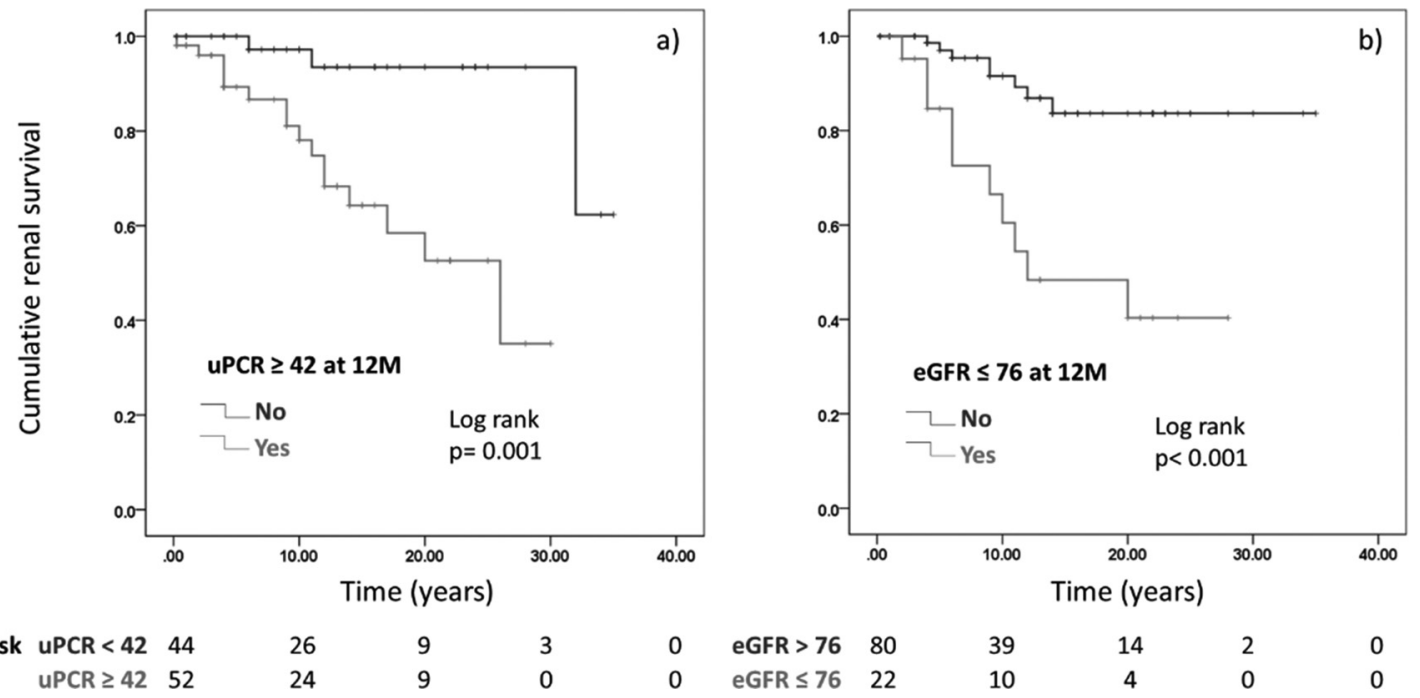

Abstract P59 Figure 1 Kaplan-meier curves showing cumulative renal survival for patients with LN 
Abstract P59 Table 1 Hazard ratio (HR) for possible predictors of ESRD, when the variables were analysed in pairs with COX regression analysis

\begin{tabular}{|c|c|c|}
\hline Cox Regression & HR $[95 \% \mathrm{Cl}]$ & p \\
\hline $\mathrm{UPCR} \geq 42$ at $12 \mathrm{M}$ & $6.365[1.431-28.321]$ & 0.015 \\
\hline eGFR $\leq 76$ at $12 \mathrm{M}$ & $8.041[2.831-22.834]$ & $<0.001$ \\
\hline $\mathrm{uPCR} \geq 42$ at $12 \mathrm{M}$ & $8.027[1.820-35.401]$ & 0.006 \\
\hline Ethnicity (AC) & $1.200[0.361-3.989]$ & 0.766 \\
\hline eGFR $\leq 76$ at $12 \mathrm{M}$ & $6.800[2.490-18.572]$ & $<0.001$ \\
\hline Ethnicity (AC) & $4.138[1.235-13.870]$ & 0.021 \\
\hline $\mathrm{UPCR} \geq 42$ at $12 \mathrm{M}$ & $9.229[2.104-40.481]$ & 0.003 \\
\hline Histological class (III or IV) & $286141.61[<0.001-7.149 \mathrm{E}+187]$ & 0.953 \\
\hline eGFR $\leq 76$ at $12 \mathrm{M}$ & $4.300[1.633-11.321]$ & 0.003 \\
\hline Histological class (III or IV) & $233853.34[<0.001-1.219 \mathrm{E}+192]$ & 0.955 \\
\hline $\mathrm{UPCR} \geq 42$ at $12 \mathrm{M}$ & $5.204[1.169-23.163]$ & 0.030 \\
\hline eGFR $\leq 82$ at $L N$ diagnosis & $4.660[1.476-14.713]$ & 0.009 \\
\hline $\mathrm{UPCR} \geq 42$ at $12 \mathrm{M}$ & $5.489[1.226-24.574]$ & 0.026 \\
\hline $\mathrm{UPCR} \geq 262$ at LN diagnosis & $2.739[0.939-7.992]$ & 0.065 \\
\hline eGFR $\leq 76$ at $12 \mathrm{M}$ & $4.030[1.548-10.495]$ & 0.004 \\
\hline UPCR $\geq 262$ at LN diagnosis & $2.195[0.826-5.836]$ & 0.115 \\
\hline $\mathrm{UPCR} \geq 42$ at $12 \mathrm{M}$ & 7.119 [1.615-31.385] & 0.010 \\
\hline No antimalarials & $3.828[1.360-10.778]$ & 0.011 \\
\hline eGFR $\leq 76$ at $12 \mathrm{M}$ & 3.659 [1.337-10.011] & 0.012 \\
\hline No antimalarials & $2.382[0.857-6.621]$ & 0.096 \\
\hline $\mathrm{UPCR} \geq 42$ at $12 \mathrm{M}$ & $5.051[1.097-23.349]$ & 0.038 \\
\hline$\%$ Diastolic BP > $80 \mathrm{mmHg}$ & $1.010[0.0990-1.030]$ & 0.347 \\
\hline $\mathrm{eGFR} \leq 76$ at $12 \mathrm{M}$ & $3.554[1.214-10.407]$ & 0.021 \\
\hline$\%$ Diastolic BP > $80 \mathrm{mmHg}$ & $1.012[0.992-1.032]$ & 0.239 \\
\hline
\end{tabular}

UPCR: urinary protein-creatinine ratio, $\mathrm{mg} / \mathrm{mmol}$; eGFR: estimated glomerular filtration rate, $\mathrm{mL} / \mathrm{min} / 1.73 \mathrm{~m}^{2}$; BP: blood pressure

Methods Single-centre retrospective observational study. Patients with biopsy-proven proliferative, membranous or mixed LN were included. Individual clinical files were reviewed to obtain demographic, clinical, laboratory and pathological data. Cox regression analysis was performed to investigate predictors of progression to ESRD and KaplanMeier curves were obtained.

Results We studied $187 \mathrm{LN}$ patients (135 proliferative, 38 membranous and 14 mixed LN), followed for up to 42 years (mean $13 \pm 9$ years). Cumulative renal survival rates at 5, 10, 15 and 20 years were 93\%, 85\%, 78\% and 70\%, respectively. In univariable analysis, urinary protein/creatinine ratio (uPCR) above $42 \mathrm{mg} / \mathrm{mmol}$ or estimated glomerular filtration rate (eGFR) below $76 \mathrm{~mL} / \mathrm{min} / 1.73 \mathrm{~m}^{2}$, one year after the diagnosis of $\mathrm{LN}$, were the strongest predictors of progression to ESRD (figure 1), with hazard ratios (HR) of 8.081 [95\%
CI:1.856-35.179] and 4.985 [95\%CI:1.964-12.651], respectively. HR for uPCR and eGFR at the time of diagnosis were considerably smaller (2.508 [95\%CI:1.062-5.922] and 2.833 [95\%CI:1.156-6.945] respectively). Other factors associated with increased risk of ESRD were Afro-Caribbean ethnicity $(\mathrm{HR}=3.861 \quad$ [95\%CI:1.817-8.206]), proliferative LN $(\mathrm{HR}=3.423$ [95\%CI:1.049-11.173]), not having taken antimalarials $(\mathrm{HR}=2.180$ [95\%CI:1.089-4.363]) and poorly controlled diastolic blood pressure $(\mathrm{HR}=1.016$ [95\%CI:1.0011.030]). The effect of uPCR and eGFR at one year remained significant after adjusting for ethnicity, histological class, uPCR and eGFR at the time of diagnosis, use of antimalarials and diastolic blood pressure (table 1).

Conclusions uPCR above $42 \mathrm{mg} / \mathrm{mmol}$ and eGFR below 76 $\mathrm{mL} / \mathrm{min} / 1.73 \mathrm{~m}^{2}$, one year after the diagnosis of $\mathrm{LN}$, were the strongest predictors of progression to ESRD. 